\title{
Cardiac MR imaging and MR angiography in pediatric congenital heart disease: a comparison between $1.5 \mathrm{~T}$ and $3.0 \mathrm{~T}$
}

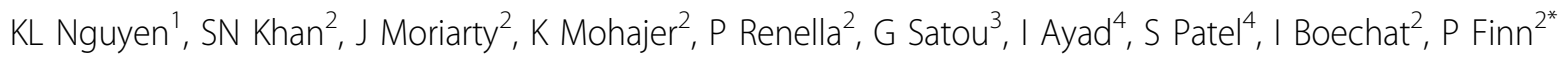

From 16th Annual SCMR Scientific Sessions

San Francisco, CA, USA. 31 January - 3 February 2013

\section{Background}

To assess the feasibility of cardiac magnetic resonance imaging (MRI) and angiography (MRA) at 3.0T in pediatric patients with congenital heart disease (CHD) and to compare the technical and diagnostic performance with an age-matched and clinically comparable control group imaged at $1.5 \mathrm{~T}$.

\section{Methods}

Forty-six patients (age 1 day to 8 years, mean $37.2 \pm$ 32.8 months) with suspected or known CHD were evaluated (9/2008-5/2011). SSFP cine imaging, timeresolved MRA (TR-MRA), and high resolution contrast-enhanced MRA (HR-MRA) were performed. Two independent observers analyzed the MRI data for

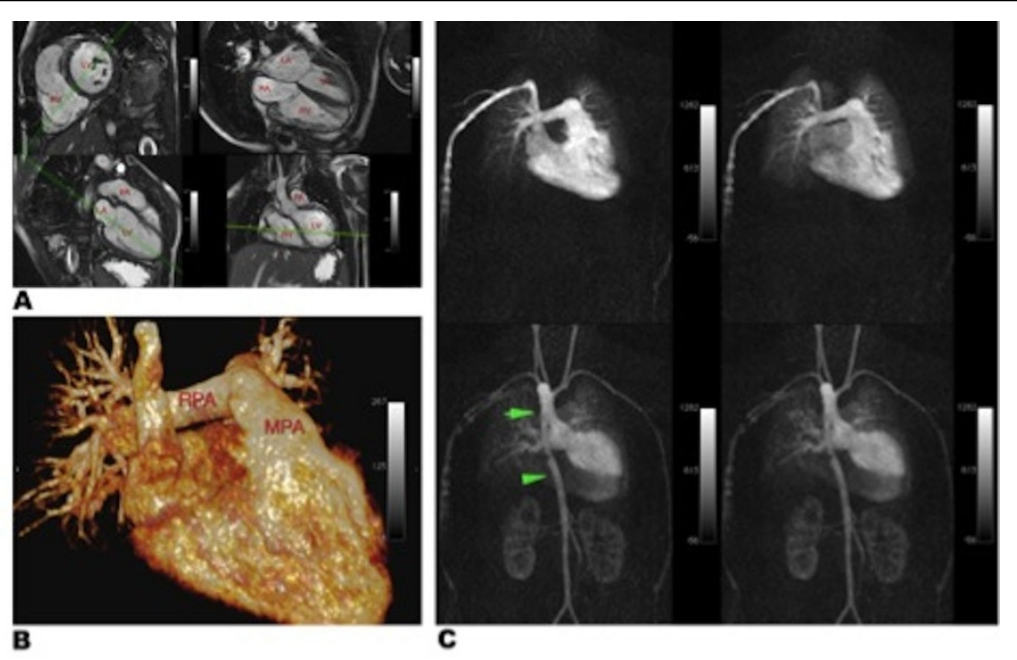

Figure 1 Six-year-old patient with Tetralogy of Fallot following complete repair with a monocuspid pulmonary valve, right ventricular outflow tract (RVOT) muscle resection and transannular patch placement, and free pulmonary regurgitation imaged at 1.5T. (A) SSFP cine images showing right ventricular hypertrophy and dilatation. (B) 3D volume rendered image showing enlarged main (22mm) and right (14mm) pulmonary arteries. (C) Time resolved CE-MRA demonstrates typical sequence of contrast opacification from a right peripheral vein and symmetric pulmonary parenchymal opacification without evidence of shunting (upper row). There is a right sided aortic arch with waisting of the descending aorta (lower row).

${ }^{2}$ Radiology, UCLA, Los Angeles, CA, USA

Full list of author information is available at the end of the article

C 2013 Nguyen et al; licensee BioMed Central Ltd. This is an Open Access article distributed under the terms of the Creative Commons 
image quality, thoraco-abdominal vessel definition, and artifacts.

\section{Results}

At $3.0 \mathrm{~T}, 91 \%$ of SSFP cine images $(\mathrm{k}=0.55)$ and $97 \%$ (374 of 387) of vascular segments $(\mathrm{k}=0.49)$ were rated as good or excellent image quality with $72 \%$ of SSFP cine images having mild and $27 \%$ having moderate artifacts. At $1.5 \mathrm{~T}, 92 \%$ of SSFP cine images $(\mathrm{k}=0.52)$ and $96 \%$ (344 of 356) of vascular segments $(\mathrm{k}=0.18)$ were rated as good or excellent image quality with $86 \%$ of SSFP cine images having mild and 14\% having moderate artifacts. The SNR and CNR of SSFP images and HR-MRA were higher at 3.0T $(\mathrm{p}<0.001)$ with off-resonance artifacts being more prevalent at $3.0 \mathrm{~T}$ ( $45 \%$ of images at $3.0 \mathrm{~T}$ vs $27 \%)$. However, they rarely rendered the images nondiagnostic.

\section{Conclusions}

Cardiac MRI \& MRA at 3.0T are feasible in children with CHD. Both field strengths can be used successfully for cardiac and vascular imaging; deciding which to use depends on local availability and the importance of vascular (extra-cardiac) vs. intra-cardiac imaging.

\section{Funding}

Siemens Research Grant.

\section{Author details}

${ }^{1}$ Cardiology, UCLA, Los Angeles, CA, USA. ${ }^{2}$ Radiology, UCLA, Los Angeles, CA, USA. ${ }^{3}$ Pediatric Cardiology, UCLA, Los Angeles, CA, USA. ${ }^{4}$ Anesthesia, UCLA, Los Angeles, CA, USA.

Published: 30 January 2013

doi:10.1186/1532-429X-15-S1-W27

Cite this article as: Nguyen et al:: Cardiac MR imaging and MR angiography in pediatric congenital heart disease: a comparison between 1.5T and 3.0T. Journal of Cardiovascular Magnetic Resonance 2013 15(Suppl 1):W27.
Submit your next manuscript to BioMed Central and take full advantage of:

- Convenient online submission

- Thorough peer review

- No space constraints or color figure charges

- Immediate publication on acceptance

- Inclusion in PubMed, CAS, Scopus and Google Scholar

- Research which is freely available for redistribution

Submit your manuscript at www.biomedcentral.com/submit 